\title{
On Contributing to the Progress of Medical Informatics as Publisher
}

\section{Congratulations to IMIA Honorary Fellow Dieter Bergemann on his 80 th Birthday!}

R. Haux ${ }^{1, m, y}$, A. Geissbuhler ${ }^{2, y}$, J. Holmes ${ }^{3, y}$, M.-C. Jaulent ${ }^{4, y}$, S. Koch ${ }^{5, M}$, C. A. Kulikowski ${ }^{6, y}$, C. U. Lehmann ${ }^{8, A, y}$, A. T. McCray ${ }^{7, m, y}$, B. Séroussi ${ }^{4,9, y}$, L. F. Soualmia ${ }^{4,10, Y}$, J. H. van Bemmel ${ }^{11, m, y}$

1 Peter L. Reichertz Institute for Medical Informatics, University of Braunschweig and Hannover Medical School, Germany

2 Department of Radiology and Medical Informatics, University of Geneva, Geneva, Switzerland

3 Institute for Biomedical Informatics, University of Pennsylvania Perelman School of Medicine, Philadelphia, Pennsylvania, USA

4 Sorbonne Universités, UPMC Univ Paris 06, INSERM, Sorbonne Paris Cité, Université Paris 13, LIMICS, UMR S 1142, Paris, France

${ }^{5}$ Department of Learning, Informatics, Management and Ethics, Health Informatics Centre, Karolinska Institutet, Stockholm, Sweden

6 Department of Computer Science, Rutgers - The State University of New Jersey, USA

7 Department of Biomedical Informatics, Harvard Medical School, Boston, Massachusetts, USA

8 Departments of Biomedical Informatics and Pediatrics, Vanderbilt University Medical Center, Nashville, TN, USA

9 AP-HP, Hôpital Tenon, Département de Santé Publique, Paris, France

${ }^{10}$ Normandie University, Rouen University, Rouen, France

"Department of Medical Informatics, Erasmus Medical Center, Rotterdam, The Netherlands

A Editor-in-Chief of Applied Clinical Informatics

M Editor-in-Chief of Methods of Information in Medicine

Y Editor-in-Chief of the IMIA Yearbook of Medical Informatics

$m$ Past Editor-in-Chief of Methods of Information in Medicine

y Past Editor-in-Chief of the IMIA Yearbook of Medical Informatics

\section{Summary}

May 1st, 2017, will mark Dieter Bergemann's 80th birthday. As Chief Executive Officer and Owner of Schattauer Publishers from 1983 to 2016, the biomedical and health informatics community owes him a great debt of gratitude. The past and present editors of Methods of Information in Medicine, the IMIA Yearbook of Medical Informatics, and Applied Clinical Informatics want to honour and thank Dieter Bergemann by providing a brief biography that emphasizes his contributions, by reviewing his critical role as an exceptionally supportive publisher for Schattauer's three biomedical and health informatics periodicals, and by sharing some personal anecdotes. Over the past 40 years, Dieter Bergemann has been an influential, if behind-the-scenes, driving force in biomedical and health informatics publications, helping to ensure success in the dissemination of our field's research and practice.

\section{Keywords}

International Medical Informatics Association, IMIA, publications

Yearb Med Inform 2017:9-15

http://dx.doi.org/10.15265/IY-2017-003

Published online May 8, 2017

\section{Introduction}

May 1st, 2017, will mark Dieter Bergemann's $80^{\text {th }}$ birthday. As Chief Executive Officer (CEO) and Owner of Schattauer Publishers (Schattauer Verlag) from 1983 to 2016, the biomedical and health informatics community owes him a great debt of gratitude. Through his vision and his enthusiastically steadfast support, three scientific informatics periodicals are now being published by Schattauer: Methods of Information in Medicine, the IMIA Yearbook of Medical Informatics, and Applied Clinical Informatics. In recognition of his outstanding contributions to the intellectual 
and scientific advances of biomedical and health informatics as a major publisher for our field, the International Medical Informatics Association (IMIA), awarded him in 2006 the title of Honorary Fellow (Figure 1). $\mathrm{He}$ is the only person outside the academic medical informatics community, who ever received this distinguished fellowship award.

In this article, the past and present editors of Methods of Information in Medicine, the IMIA Yearbook of Medical Informatics, and Applied Clinical Informatics want to honour and thank Dieter Bergemann

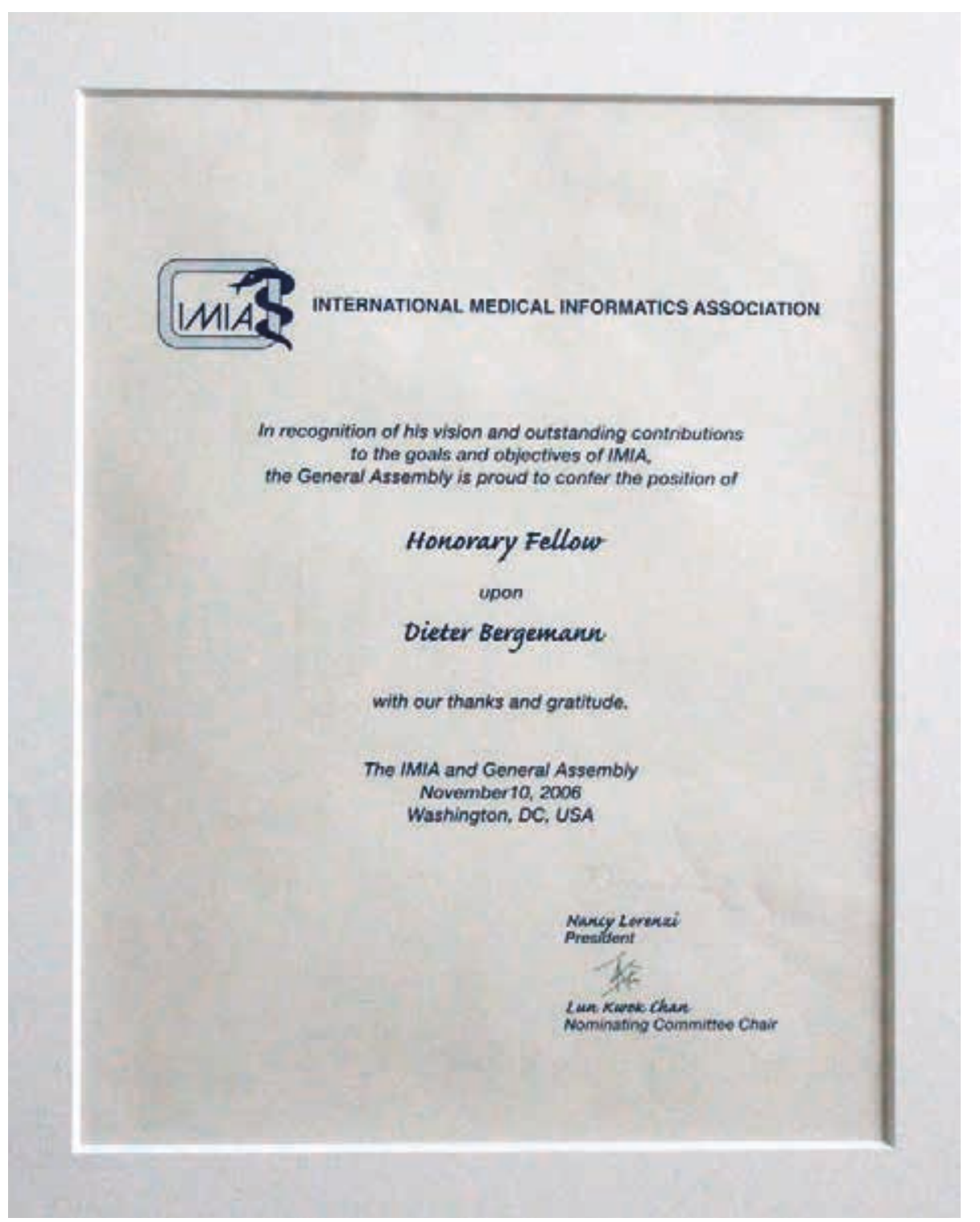

Fig. 1 IMIA Honorary Fellow certificate for Dieter Bergemann. Picture, taken in 2016, at his office at Schattauer, Stuttgart, Germany.
- by providing a brief biography that emphasizes Dieter Bergemann's contributions for the readership of the Yearbook of Medical Informatics and to the international biomedical and health informatics community (section 2),

- by reviewing Dieter's critical role as an exceptionally supportive publisher for Schattauer's three biomedical and health informatics periodicals (section 3), and

- by sharing some personal anecdotes (section 4).

\section{From Typesetter to Publisher and CEO - a Short Biography}

Dieter Bergemann was born on May 1st, 1937 in Frankfurt/Main, Germany, where he also grew up and attended primary and high school (Gymnasium). He then moved to Schorndorf, a city close to Stuttgart, for an apprenticeship (Lehre) as typesetter. There he successfully passed his master's examination in typesetting at the local Chamber of Industry and Commerce.

In 1969, he became an authorized officer (Prokurist) and, later, shareholder of Mayr Miesbach, a printing company, located in Miesbach, south of Munich. In 1973, he founded the publishing house Bergemann + Mayr. Close to Miesbach, the town of Schliersee became home to Dieter and his wife Helga. Located on Lake Schliersee, this town enjoys one of the most beautiful landscapes in Germany.

In 1983, Dieter Bergemann became the owner of Schattauer Publishers, a publishing house in Stuttgart, and in 1985, he became its commercial CEO (kaufmännischer Geschäftsführer). This development arose from the close collaboration between the Mayr Miesbach printing company and the Schattauer publishing house even before Dieter assumed ownership of Schattauer.

During his time as owner and CEO, Schattauer Publishers successfully developed as a medium-sized publishing house for books and journals in medicine and the life and natural sciences. Success for Dieter Bergemann always consisted of two parts. Being economically profitable in the long term was the necessary, but by no means the sufficient condition. Dieter's first priority was that the books and journals, published by Schattauer, together with Schattauer's services for authors and editors were of the highest quality to ensure that Schattauer publications would make significant contributions to progress in medicine, health care, and their supporting sciences. The range of books and journals published by Schattauer now spans nearly all fields of medicine and the health sciences, including biomedical and 
health informatics. Among the outstanding advantages for authors and editors of Schattauer Publishers was the close personal relationships with Dieter Bergemann as well as with the whole Schattauer team. These relationships often lasted for decades and were frequently rekindled with meetings taking place in his office (Figure 2).

His close ties to biomedical and health informatics as a scientific discipline and to the International Medical Informatics Association were well demonstrated by artefacts found in his office. Among the pictures, two were related to medical informatics: The IMIA certificate, conferring to Dieter the Honorary Fellowship (Figure 1) and a 2007 drawing made by the daughter of the corresponding author, which visually presents the two informatics periodicals published at this time, together with Dieter's publishing house and printing company (Figure 3 ).

In 2016, after more than 30 years of leadership, Dieter Bergemann, decided to retire and to sell Schattauer Publishers. Since 2017, it has been part of Thieme Medical Publishers. Like Schattauer, Thieme is a privately owned and operated publishing house, also located in Stuttgart.

Last, but not least, we note Dieter Bergemann's broader service to the business and professional community, having been Honorary Commercial Judge for the Regional Court Munich II (from 1984 to 2007) and Member of the General Assembly of the Chamber of Industry and Commerce Munich / Upper Bavaria (from 1984 to 2001). In 2004, he received the Cross of Merit with ribbon of the Order of Merit of the Federal Republic of Germany.

\section{Dieter Bergemann's Publishing Leadership and Schattauer's Informatics Periodicals}

As mentioned earlier, Schattauer now has three informatics publications: Methods of Information in Medicine (Methods), the IMIA Yearbook of Medical Informatics, and Applied Clinical Informatics (ACI).

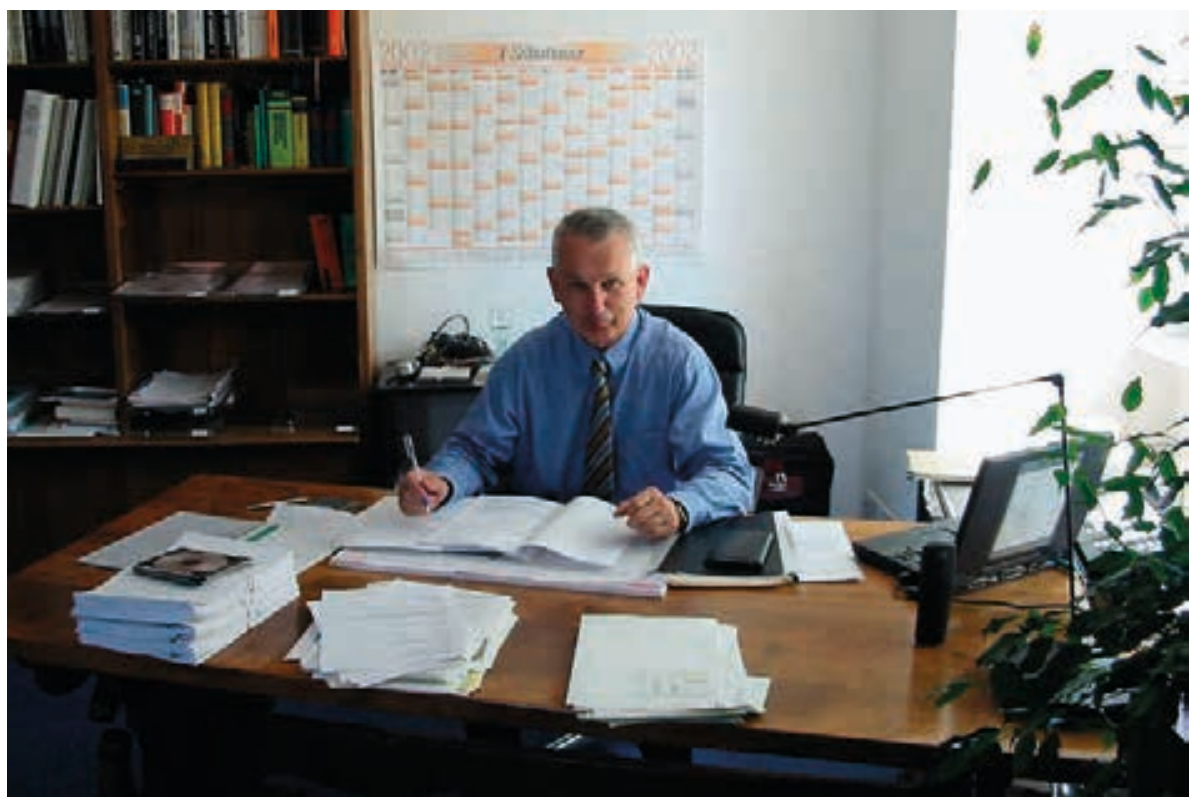

Fig. 2 Dieter Bergemann in his office at Schattauer, Stuttgart, Germany. Picture, taken on May 16, 2002.

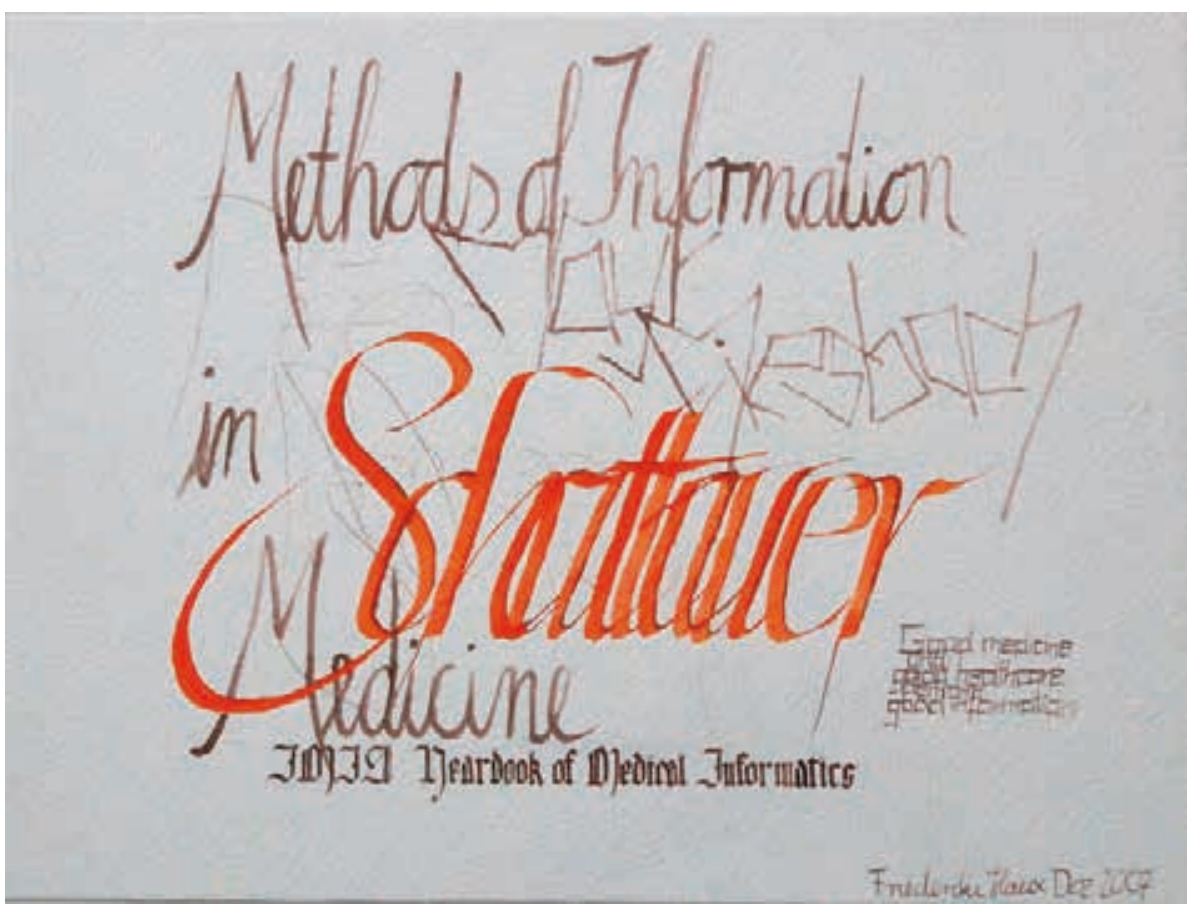

Fig. 3 Drawing from 2007, visualizing the two informatics periodicals published at this time, and Schattauer as well as Mayr Miesbach. Picture, taken in 2016, at Dieter Bergemann's office at Schattauer, Stuttgart, Germany.

Methods of Information in Medicine

Founded in 1962, the journal Methods of Information in Medicine, "devoted to information in biomedicine and health care" [1], became, in 1965, the first informatics journal published by Schattauer. From 1983 until his retirement in 2016, Dieter Bergemann was intimately involved with the development of the journal [1]. Figure 4 is one of the few photos taken at an editors-publisher meeting in 2003 in Heidelberg, showing Dieter Bergemann together with Gustav Wagner, the 


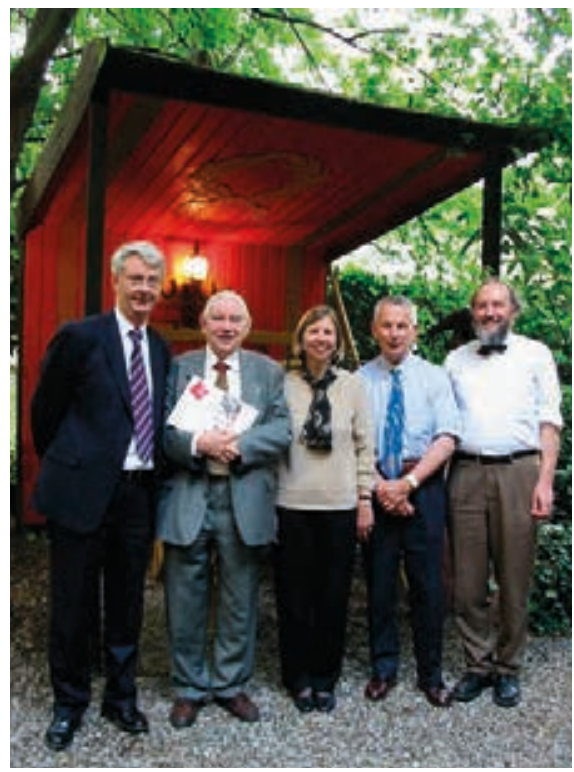

Fig. 4 Methods editors-publisher meeting on May 9, 2003 in Heidelberg, Germany. From left to right: Jan van Bemmel, Gustav Wagner (1918-2006), Alexa McCray, Dieter Bergemann and Reinhold Haux. founding editor of Methods of Information in Medicine [2]. In 2011, to mark the $50^{\text {th }}$ anniversary of Methods, a scientific symposium on 'Biomedical Informatics: Confluence of Multiple Disciplines' took place in Heidelberg, with the support of Dieter Bergemann and of Schattauer Publishers [3]. A number of distinguished colleagues, either involved directly in the journal's development, editors of some of our international sister journals, or representatives of international medical informatics organizations, celebrated this anniversary (Figure 5). During this symposium, it was announced that all Methods articles, from 1962 onwards, were going to be made accessible through Schattauer's online archive as well as indexed in MEDLINE/PubMed [1]. Needless to say, this important step for disseminating the literature in our field would not have become possible without Dieter's support as publisher.

\section{IMIA Yearbook of Medical Informatics}

In 1990 the IMIA Board adopted an idea from Morris Collen and Marion Ball to publish an annual Yearbook of Medical Informatics. The objective was to "compile the most relevant high-quality scientific papers published in the preceding year in the field of medical informatics, and to include factual information on IMIA 's constituent Member Societies and its activities" ([4], p. 7). In search for the right publishing house, IMIA asked Dieter Bergemann, whether Schattauer Publisher's would be willing to publish this periodical in the future. He accepted and supported this publication throughout all the following years until his retirement in 2016. With his support and active promotion, the Yearbook was published as a hard-copy book from 1992 until 2013.

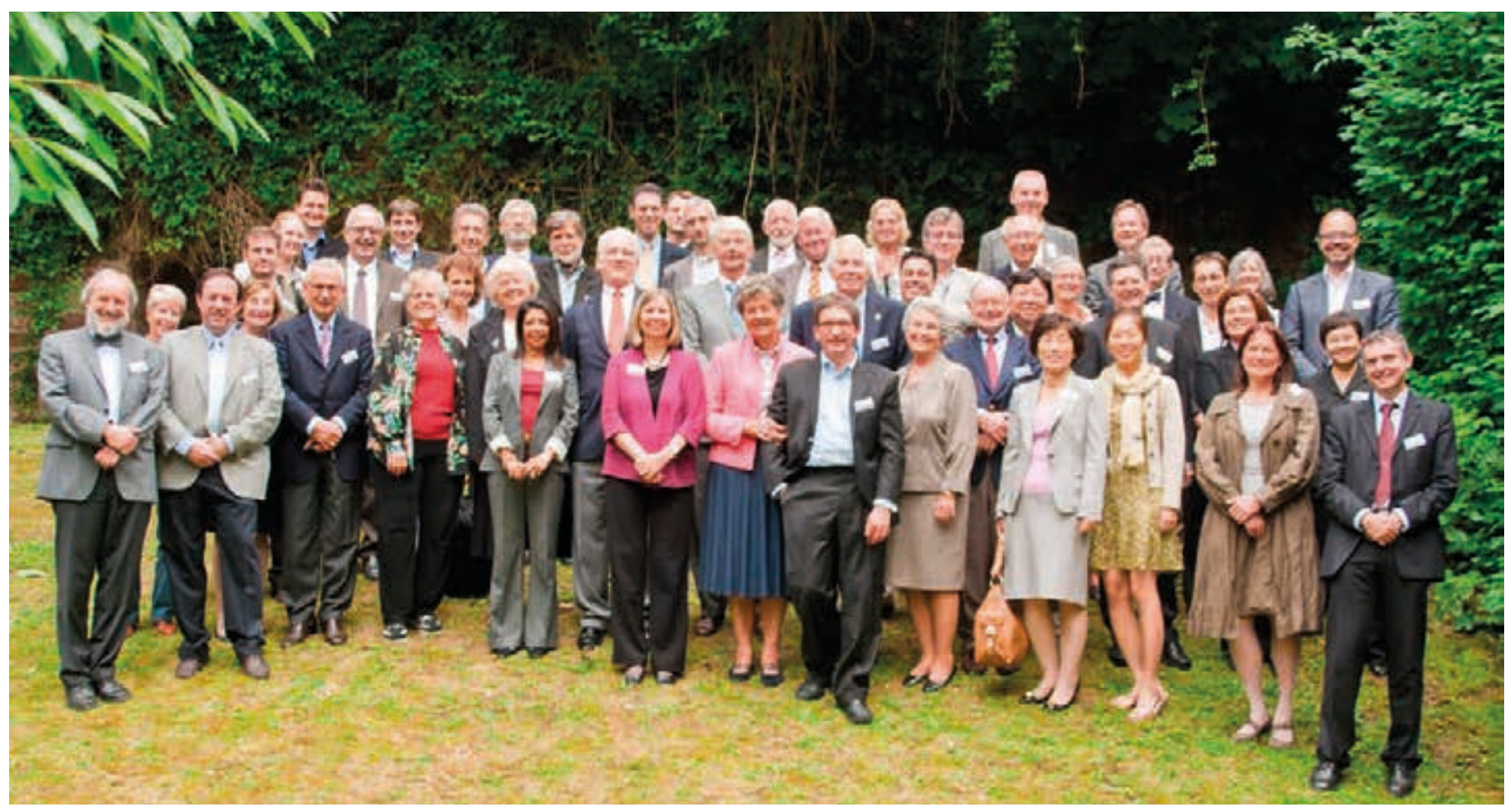

Fig. 5 Participants of the symposium 'Biomedical Informatics: Confluence of Multiple Disciplines', on the occasion of 50 years of Methods of Information in Medicine, from June 9 to 11, 2011 , at Heidelberg, Germany. From left to right: Reinhold Haux (Germany), Helga Bergemann (Germany), Victor Maojo (Spain), Marion Ball (USA), Fernando Martin-Sanchez (Australia), Corinna Scharnweber (Germany), Michael Marschollek (Germany), Dieter Bergemann (Germany), John Mantas (Greece), Klaus-Hendrik Wolf (Germany), Joyce Mitchell (USA), Petra Knaup (Germany), Riccardo Bellazzi (Italy), Jana Zvárová (Czech Republic), Katsuhiko Takabayashi (Japan), Hartmuth Dickhaus (Germany), Edward Shortliffe (USA), Dominik Aronsky (USA), Alexa McCray (USA), Olaf Gefeller (Germany), György Surján (Hungary), Jan van Bemmel (The Netherlands), An van Bemmel (The Netherlands), Jan Talmon (The Netherlands), Arie Hasman (The Netherlands), Christian Lovis (Switzerland), Donald Lindberg (USA), Fia Hasman (The Netherlands), Neil Sarkar (USA), Mary Lindberg (USA), Peter Murray (UK), Casimir Kulikowski (USA), Hans Peterson (Sweden), Andreas Ziegler (Germany), Michio Kimura (Japan), Hyeoun-Ae Park (South Korea), Ulla Gerdin (Sweden), Mariah Junglan Min Park (South Korea), Mark Musen (USA), Christoph Lehmann (USA), Randy Miller (USA), Elske Ammenwerth (Austria), Lucila Ohno-Machado (USA), Linda Miller (USA), Andrea Schürg (Germany), Antoine Geissbuhler (Switzerland), Tze Yun Leong (Singapore), Peter Henning (Germany). Other participants, not in the pitture: Marianna Diomidis (Greece), Jan Haaf (Germany). More details in [2]. 
From 2006 onwards, it also became available online at Schattauer, and since 2014 in gold open access. In 2016, to celebrate the IMIA Yearbook's 'Silver Anniversary' [7], IMIA and Schattauer announced that beginning in 2016 all Yearbook volumes would be accessible through Schattauer's online archive as well as being indexed in MEDLINE/PubMed. This action shows how the first sentence written by IMIA President Jos Willems in 1992 "This was only possible thanks ... to the generous help of Schattauer Publishing Company" ([3], p. 7) is something strongly pursued and emphasized by Dieter Bergemann during his stewardship of Schattauer Publishers. Figure 6 shows a picture of Dieter Bergemann in 2013 in front of the Schattauer building together with the then Yearbook editors-in-chief Marie-Christine Jaulent and Brigitte Séroussi (the third editor-in-chief, Christoph Lehmann, participated in this meeting through video conference) and with the Yearbook ${ }^{6}$ s most essential and devoted long-time Editorial Assistant Martina Hutter.

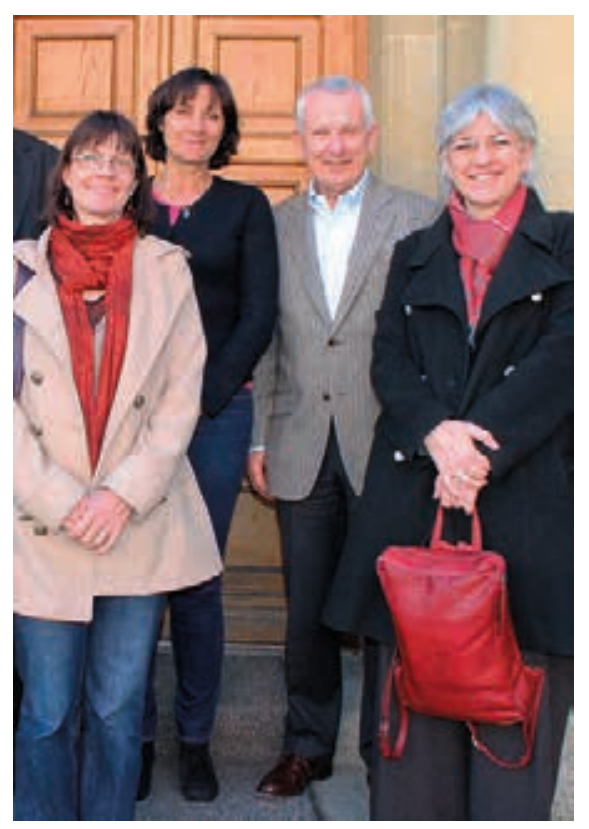

Fig. 6 IMIA Yearbook editors-publisher meeting on March 7, 2013 at Stuttgart, Germany. Dieter Bergemann is surrounded by (from left to right) MIA Yearbook Editorial Assistant Martina Hutter, MIA Yearbook editors Brigitte Séroussi and Marie-Christine Jaulent.

\section{Applied Clinical Informatics}

Triggered by Marion Ball and by the corresponding author, in 2008 it became clear that for the international medical informatics community an international journal, focussing on applied informatics topics in an independent scientific way was needed [8]. Dieter Bergemann was again contacted by IMIA leaders and was asked whether such a new journal could be launched at his publishing house. After a day-long discussion on content, readership, and financial risks, he finally accepted and the journal Applied Clinical Informatics $(A C I)$ was launched as first pure online journal at Schattauer Publishers. Although having assigned the publisher's responsibilities primarily to his co-CEO Jan Haaf, who shepherded the journal until 2017, he also carefully monitored $A C I$ 's development until his retirement. Figure 7 shows Dieter Bergemann with $A C I$ editor-in-chief Christoph Lehmann at the end of their very first editor-publisher meeting.

\section{Some Personal Anecdotes A Valued Colleague (A.T.M.)}

I first had the pleasure of meeting Dieter Bergemann when Jan van Bemmel and I began our work on the Yearbook in the early 1990's. As editor of Methods, Jan had already worked closely with Dieter for several years on the publication of that journal. At our first meeting with Dieter in Stuttgart to discuss the Yearbook, I was immediately struck by the personal and cordial relationship between Jan and Dieter. I was also surprised that the owner and CEO of a busy publishing house would spend an entire day with the editors of one of its (many) publications and, further, that he was fully aware of the details of what we were trying to accomplish. Dieter was kind enough to welcome me warmly as one of his editors during that first meeting. From that day forward, including when I became editor, together with Reinhold Haux, of Methods, I realized that it was important to Dieter, not only as a businessman, but also as a person, to establish and maintain a friendly and ongoing relationship with the editors of his publications. Over the years, that rela-

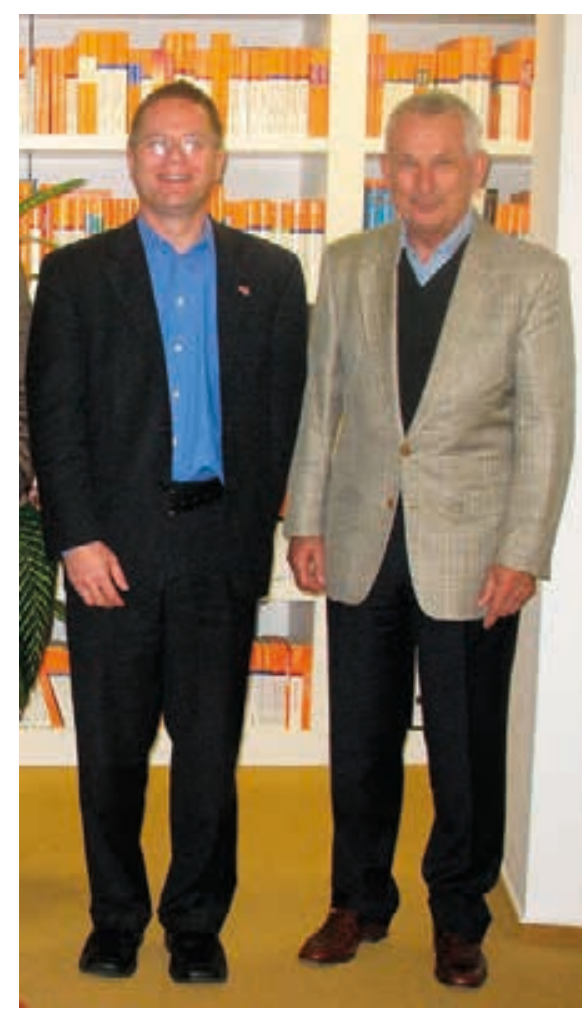

Fig. 7 Initial Applied Clinical Informatics editor-publisher meeting on September 16, 2008, at Stuttgart, Germany, with Christoph Lehmann and Dieter Bergemann.

tionship has made it possible to maintain the smooth running of our publications, allowed us to resolve sometimes prickly issues, and, importantly, made it possible for us to introduce innovations. Throughout, Dieter has remained a gracious and valued colleague who has, through his commitment to the dissemination of the findings in our field, contributed substantially to the health of the international medical informatics field.

\section{Building Trust and Loyalty (C.U.L.)}

In 2009, Professor Haux reached out to Schattauer Verlag and arranged for a meeting with Schattauer's Dieter Bergemann, Peter Henning, Andrea Schürg, and Jan Haaf. Prof. Haux and I spent all day on the top floor of the Stuttgart office of Schattauer trying to convince Dieter Bergemann and his team to launch a new journal in clinical informatics, but the Schattauer team remained sceptical. At the end of the day, Mr Bergemann had 
invited us, his team, and my wife to dinner in a lovely local restaurant serving authentic local food. By the end of the evening, we had an agreement - Schattauer would give it a try and publish a new online journal in clinical informatics. I never learned what changed Dieter Bergemann's mind. Was it the "Gemuetlichkeit" of the event and the group, did our arguments finally convince him, or was it the charm of my wife?

Over the years, I came to appreciate and cherish the close contacts with Schattauer Publishers, the open communication, and the support given to my authors and reviewers. I realized that this was part of the business model for Schattauer - build trust and loyalty with your editors and authors, support them, and they will in turn deliver high quality papers that will draw attention. For $A C I$ this attention came when it became in addition to an official IMIA journal also an official journal of the American Medical Informatics Association.

\section{Dieter's Uniquely Personal Touch - in Life as in Publishing (C.A.K.)}

During the time I served as co-editor of the IMIA Yearbook of Medical informatics with Reinhold Haux, we would invariably get together with Dieter Bergemann during the main annual editorial meeting. I always found him most friendly and attentive to the editorial discussions, and especially interested in how we selected the content of the annual volume. We would also enjoy editorial dinners together, where we enjoyed hearty fare in Heidelberg, Innsbruck, and Braunschweig, as well as Katharina Haux's excellent cooking in Meckesheim (near Heidelberg) and Wolfenbüttel (near Braunschweig). I got to meet Dieter's wife Helga and learn of their deep interests in learning and shared enjoyment in travel, which always led to interesting discussions while comparing our experiences. When in Wolfenbüttel, Reinhold Haux would treat us to visits of the old town, the castle and the Duke August Library with its incredible collection of manuscripts, medieval and renaissance books and artifacts - as well as the impressively enlightening Lessing House. Dieter was always invaluable in commenting and clarifying details about the collections and how they bear on the history illustrating the evolution of ideas, styles, and printing. On one occasion, after our editorial meetings, Dieter and his wife Helga invited me for a drive in the country, and we enjoyed a half-day together going though the villages in the Elm hills, including the historical town of Königslutter, famous for its Romanesque Benedictine Monastery founded by Lothair III who is buried there. It was while talking informally and leisurely during our trip that I came to fully appreciate Dieter's deep love of knowledge, and his insights into so much, but especially the many medical topics he has become immersed in over the years while heading Schattauer. His passion for ensuring the quality of the information that his company prints came through vividly and showed me why he has been, not only a good friend, but also such an influential, if behind-the-scenes, driving force in biomedical and health informatics publications, helping to ensure success in the dissemination of our field's research and practice over the past 40 years!

\section{He Always Kept his Promises (J.H.v.B.)}

During the years that I was the editor-in-chief of the journal Methods of Information in Medicine and when I edited the Yearbook of Medical Informatics with Alexa McCray, I had many 'business contacts' with Dieter Bergemann. When decisions had to be made, I was always impressed by his very positive feelings towards our discipline. Methods was already in good shape during the time of the editorship of Gustav Wagner, my direct predecessor. The Yearbook was founded much later and I remember very well the outstanding collaborative attitude on how to proceed in producing the Yearbooks. As the Director of Schattauer Verlag, the publisher of both Methods and the Yearbooks, Dieter had a very great advantage: he was also the owner of a large and exceptionally modern and automated four-color printing office in Miesbach, a city close to the Alps in Bavaria. Several times, I visited both his Schattauer Office in Stuttgart and his printing plant in Miesbach. Dieter and Helga's house is located nearby, close to the beautiful Schliersee, a lake that is part of the German Alps.
The first time I visited Miesbach, I flew from Amsterdam to Munich, and was picked up by Dieter in his Audi Quattro, a red car he still drives until today. Apparently, Dieter wanted to show that it was not only possible to fly in the air, but also on the 'Autobahnen', the German highways, with hardly any speed limits. We drove at a tempo (that's the German term) of at least $220 \mathrm{~km} / \mathrm{h}$. From then on, I was convinced of Dieter's perseverance. Moreover, when an agreement had been made, he always kept his promises. Outside mere business contacts, my wife Ann and I always enjoyed great personal rapport with Helga and Dieter. Proof of it is that they visited us several times - most recently during the winter of 2017 - when we were on vacation in Austria, south of Salzburg. I was a bit surprised that it took Dieter more than two hours to drive from Miesbach to south of the Dachstein mountain. I didn't ask him, but perhaps he is now aware that he is really retired. Regardless, we look forward to getting together again: the next time once more in The Netherlands.

\section{What it Means to Be a True Publisher (R.H.)}

Dieter and I have known each other since the early 1990's, after which most of the German textbooks in medical informatics to which I have contributed as co-author, are published by Schattauer. During my time as an editor of Methods, between 2001 and 2015, and of the IMIA Yearbook, between 2001 and 2007, I have had at least one meeting per year with Dieter in Stuttgart. I think it will be illuminating to share three anecdotes about such meetings.

The early annual editor-publisher meetings at Stuttgart were, to my surprise, usually opened by Dieter with quite strong criticism on how Methods and/or the Yearbook were too expensive. He asked me to either make proposals on how costs could be cut or at least more controlled, or on how the income they generated could be increased. I understood this well from a commercial perspective, but explained to Dieter that some publishing houses of related journals were providing better support to authors, readers, reviewers, and editors, and that this was a disadvantage to the competitiveness of 
Methods and/or of the Yearbook. Then, and during the years that followed, the outcome of these meetings were always careful considerations and decisions on how we could jointly provide better services, considering also the economic constraints and requirements of editing and publishing. These meetings usually started in the afternoon. In the evening Dieter invited me and some colleagues of the Schattauer team to a very good and very typical Swabian restaurant with local food (having grown up close to Stuttgart I very much enjoyed this cuisine, which reminded me of my youth). Again, to my surprise, all conflicts and debates of the afternoon were completely forgotten and we would all have a most enjoyable and informal time together.

In about 2005, the IMIA Yearbook found itself in a financial crisis, as the result of some of IMIA's member societies not wanting to continue to pay for the Yearbook. In this very critical situation, I asked Dieter for his help and advice. We carefully analyzed the situation. As far as I can tell, Schattauer Publishers reduced or even waived the fees for their services for some years. The Yearbook was able to be reshaped, its services were renewed in a timely manner and the crisis was overcome, thanks to Dieter's deep commitment to maintaining a flagship operation of IMIA and to the benefit of the biomedical and health informatics community. A publication manager, only looking strictly at the economic facts, would probably have stopped publishing the Yearbook. Dieter, as owner and CEO, and as a true and committed publisher, recognizing the long-term impact of the IMIA Yearbook, was willing and able to make the appropriate long-term decisions, for the benefit of our field and for the benefit of his publishing house.

In 2017, Methods of Information in Medicine launched with Methods Open a gold open access track [5]. Supported by Deutsche Forschungsgemeinschaft, our objective is to develop a better understanding of how traditional subscription-based journals can be transformed to open access journals by currently running the Trans-O-MIM project [6]. Initial thoughts and discussions go back to 2013. Dieter saw these developments towards open access and accepted the need to improve scientific communication. $\mathrm{He}$ also clearly stated his doubts about whether this approach will prove to be economically feasible. In spite of his doubts and after many discussions, he finally accepted that I will move forward in applying for the Trans-OMIM project and he co-signed this proposal in his role of publisher. In his unique role as a publisher, devoted to contributing so strongly to the progress of medical and health care, and to the life sciences, he accepted the responsibility of running this project, in spite of his concerns. Even more, until his retirement in 2016, he actively participated in the project's steering committee.

From Dieter I have learned what it means to be a true publisher in the traditional sense, but with the business acumen to face the changes required by this digital age, where informatics with all its opportunities and challenges, has become such a central concern.

\section{Thank you and our Best Wishes!}

Dieter, we are aware that, with your most becoming modesty, you may not have wished that this kind of article be published. Despite your many achievements, you have never sought to be honoured, particularly at public events and in publications. We nevertheless hope that you will accept our deep gratitude for all your support of IMIA and of the biomedical and health informatics community more broadly, accept the sincere appreciation of all of us, and obtain some enjoyment in reading it. To conclude: Thank you so much! Happy birthday! All the best to you and your wife in your future endeavours and adventures!

\section{Acknowledgements}

We are grateful to members of the Schattauer team, who helped us in preparing this manuscript.

\section{References}

1. McCray AT, Gefeller O, Aronsky D, Leong TY, Sarkar IN, Bergemann D, et al. The birth and evolution of a discipline devoted to information in biomedicine and health care. As reflected in its longest running journal. Methods Inf Med 2011;50:491-507.

2. Van Bemmel JH, Bergemann, D. In Memoriam. Gustav Wagner (1918 - 2006). Founding Editor of Methods. Methods Inf Med 2007;46:1.

3. Haux R. On the methodology and scientific fundamentals of organizing, representing and analysing data, information and knowledge in biomedicine and health care. Methods Inf Med 2011;50:487-90.

4. Willems JL. Preface. Yearb Med Inform 1992:7.

5. Koch S, Haux R, Gefeller O, Sarkar IN, Bergemann D. Methods Open - A New Journal Track Starting in 2017. Methods Inf Med 2016 Dec 7;55:478-80.

6. Haux R, Kuballa S, Schulze M, Böhm C, Gefeller O, Haaf J, et al. Exploring Possibilities for Transforming Established Subscription-based Scientific Journals into Open Access Journals. Present Situation, Transformation Criteria, and Exemplary Implementation within Trans-O-MIM. Methods Inf Med 2016 Dec 7;55:481-7.

7. Lehmann CU, Jaulent MC, Séroussi B. Silver Anniversary: 25 Editions of the IMIA Yearbook. Yearb Med Inform 2016; Suppl 1:S3-5.

8. Lehmann CU, Altuwaijri MM, Li YC, Ball MJ, Haux R. Translational research in medical informatics or from theory to practice. A call for an applied informatics journal. Methods Inf Med 2008;47:1-3.

\section{Correspondence to:}

Prof. Dr. Reinhold Haux

Peter L. Reichertz Institute for Medical Informatics

University of Braunschweig - Institute of Technology and Hannover Medical School

Mühlenpfordtstr. 23

38106 Braunschweig

Germany

E-mail: Reinhold.Haux@plri.de 